\title{
Treatment of Rare Gastric Variceal Bleeding in Acute Pancreatitis Using Embolization of the Splenic Artery Combined with Short Gastric Vein
}

\author{
Lixin Li Xin Zhao \\ Department of Hepatobiliary and Pancreatosplenic Surgery, Beijing Chaoyang \\ Hospital affiliated to Capital Medical University, Beijing, China
}

\section{Key Words}

Severe acute pancreatitis · Gastric varices · Splenic artery embolization

\begin{abstract}
In the acute stage of pancreatitis, sinistral portal hypertension is a rare reason for gastric variceal bleeding. Here we report a 20-year-old female patient with massive upper gastrointestinal hemorrhage 7 days after an episode of severe acute pancreatitis. Computed tomography showed gastric varices caused by splenic venous thrombosis. Emergency endoscopic examination was performed, however tissue adhesive utilized to restrain the bleeding was not successful. Although interventional therapy was controversial to treat the gastric variceal hemorrhage resulting from sinistral portal hypertension, the bleeding was successfully treated by embolization of the splenic artery combined with short gastric vein. Two weeks after the interventional the patient was discharged from our hospital without recurrence of bleeding. Embolization of the splenic artery combined with short gastric vein proved to be an effective emergency therapeutic method for gastric variceal bleeding caused by sinistral portal hypertension in the acute stage of pancreatitis.
\end{abstract}

\section{Introduction}

Upper gastrointestinal hemorrhage is a common complication of hepatic cirrhosis with systemic portal hypertension, while rarely caused by pancreatic diseases. Pancreatic diseases may induce sinistral portal hypertension (SPH), intracystic bleeding and ruptured pseudoaneurysm [1-5]. SPH is a clinical syndrome of local portal hypertension induced by splenic vein thrombosis due to primary pancreatic 
diseases, which usually include chronic pancreatitis, pancreatic pseudocysts and pancreatic carcinomas [2]. Gastric variceal bleeding resulting from SPH of severe acute pancreatitis is quite rare especially in the acute stage, having been reported only sporadically, and the definitive therapeutic method of such lesions is sometimes difficult and controversial $[6,7]$.

Here we report a patient with massive gastric variceal bleeding caused by SPH, which was induced by severe acute pancreatitis. At first, emergency endoscopic tissue adhesives were performed, nevertheless repeated bleeding occurred $12 \mathrm{~h}$ after treatment. Embolization of the splenic artery combined with short gastric vein was finally applied, and the patient was successfully treated.

\section{Case Report}

A 20-year-old parturient with an episode of severe acute pancreatitis 7 days after delivery was transferred from the department of gynecology to our ward. The patient did not have a history of chronic pancreatitis, alcohol abuse or liver cirrhosis. Physical examination was unremarkable except for mesogastric tenderness. Laboratory findings revealed an increased value of amylase (2,170 U/l, normal 37-152), with normal levels of bilirubin and transaminase. Consequently, treatment of acute pancreatitis was started. Seven days after the diagnosis of pancreatitis, the patient had onset of acute abdominal pain and hematemesis. The amount of bleeding was $700 \mathrm{ml}$ and correspondingly physical examination showed pallor of the extremities, tachycardia with $115 / \mathrm{min}$, low blood pressure of 80/40 $\mathrm{mm} \mathrm{Hg}$ and a drop in serum hemoglobin from 109 to $70 \mathrm{~g} / \mathrm{l}$. An emergency computed tomography (CT) scan had revealed a cystic lesion with a maximum diameter of $10 \mathrm{~cm}$, located between the pancreas and the stomach, associated with swelling of the pancreas, which was diagnosed as acute pancreatic pseudocyst accompanied by acute pancreatitis. Furthermore, a venous phase CT scan revealed thrombosis in the splenic vein and partial infarction of enlarged spleen (fig. 1). A diagnosis of gastric fundal varices was proposed because of the obstruction of the splenic vein and collateral blood flow via the short gastric veins (ig. 2 ).

Emergency endoscopic examination was performed and enlarged bleeding gastric varices, but no esophageal varices, were observed. Percutaneous transhepatic portography confirmed thrombosis in the splenic vein and enlargement of the short gastric veins. Extravasation of contrast materials was observed from one of the dilated short gastric veins into the gastric cavity during angiography (fig. 3 ). Based on the examination results, we concluded that gastric bleeding resulted from rupture of short gastric varices caused by severe acute pancreatitis. Tissue adhesive of $\mathrm{N}$-butyl-2-cyanoacrylate was successfully utilized to restrain the bleeding through emergency endoscopy; nevertheless, $12 \mathrm{~h}$ after the treatment, repeated bleeding occurred.

Finally, further selective celiac angiography combined with superselective splenic arteriography was performed to control the recurrent bleeding. A guidewire was directed into the splenic artery with standard percutaneous transfemoral catheterization, and a wedge balloon catheter was passed over the guidewire. Temporary embolic agent of cellulose sponge plugs was injected into the target vessel of the splenic artery (fig. 4) and permanent embolic agents of vascular coils (5 mm) were

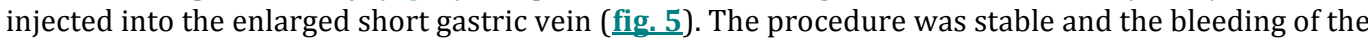
gastric varices eventually stopped. No recurrence of bleeding was noted after the embolization. In addition, during angiography, $\mathrm{N}$-butyl-2-cyanoacrylate was observed not only in the gastric varices but also in the portal vein, which suggested ectopic thrombosis from the short gastric vein to the portal vein via the coronary vein. The patient was discharged from our hospital 2 weeks later without recurrence of bleeding. 


\section{Discussion}

Hemorrhage is one of the most life-threatening complications of pancreatitis. It is usually due to gastric variceal bleeding resulting from SPH or to erosion of a major pancreatic or peripancreatic vessel or to rupture of an arterial pseudoaneurysm. $\mathrm{SPH}$ means isolated gastric varices resulting from thrombosis or obstruction of the splenic vein $[2,8]$. The diagnosis of SPH should be considered in all those with upper gastrointestinal bleeding associated with splenomegaly and normal liver function tests. The progressive enlargement of the pseudocyst induces necrotizing vessels because of the added pressure on the vessel walls and from the action of proteolytic enzymes. This leads to the erosion of the vessel walls, resulting in intracystic hemorrhage. Pseudoaneurysms of peripancreatic arteries may arise as a complication of chronic pancreatitis and can result in life-threatening hemorrhage [9]. The latter two pathologies may either bleed intra-abdominally following rupture or erode into the adjacent hollow viscera and manifest as gastrointestinal bleeding. In the present case, SPH resulted from severe acute pancreatitis leading to hemorrhage. To our knowledge, gastric variceal hemorrhage is a common vascular complication of chronic pancreatitis or pancreatic necrosis. This is the first reported case of gastric variceal bleeding resulting from SPH in the early stage of severe acute pancreatitis.

Despite recent advances in the treatment of variceal bleeding, emergent gastric variceal bleeding remains a challenge to the clinician due to its high recurrence rate. Management of bleeding from SPH involves splenectomy, ligation and embolization of the splenic artery [10]. Those measures may decrease the arterial inflow into the left portal system, resulting in decompression of the gastric varices. Furthermore, tissue adhesives have also been suggested as an alternative to splenectomy in high-risk patients or recurrent bleeding. Repeated bleeding, cerebral shock and portal vein embolization are common complications of tissue adhesives [11]. In this case, portal ectopic thrombosis may have played an important role in recurrent bleeding because $\mathrm{N}$-butyl-2-cyanoacrylate was transmitted through the short gastric veins via the coronary vein into the portal system. Subsequently, splenic artery embolization combined with short gastric vein restrained rebleeding. Although the optimal treatment of gastric variceal bleeding secondary to splenic vein thrombosis is still controversial, splenectomy is traditionally considered the first choice of treatment. However, in the emergency setting or a difficult situation such as hemodynamic instability, splenic artery embolization combined with short gastric vein is an effective, quick and safe alternative to emergency gastric variceal bleeding [12, 13].

As a rare etiology, severe acute pancreatitis may result in SPH and subsequently gastric variceal bleeding. Embolization of the splenic artery combined with short gastric vein is an effective emergency management. 


\begin{tabular}{r|l|l|l}
$\begin{array}{r}\text { Case Reports in } \\
\text { Gastroenterology }\end{array}$ & $\begin{array}{l}\text { Case Rep Gastroenterol 2012;6:741-746 } \\
\text { DOI: 10.1159/000345962 }\end{array}$ & $\begin{array}{l}\text { Published online: } \\
\text { December 11, 2012 }\end{array}$ & $\begin{array}{l}\text { @ 2012 S. Karger AG, Basel } \\
\text { ISSN 1662-0631 } \\
\text { www.karger.com/crg }\end{array}$ \\
\hline
\end{tabular}

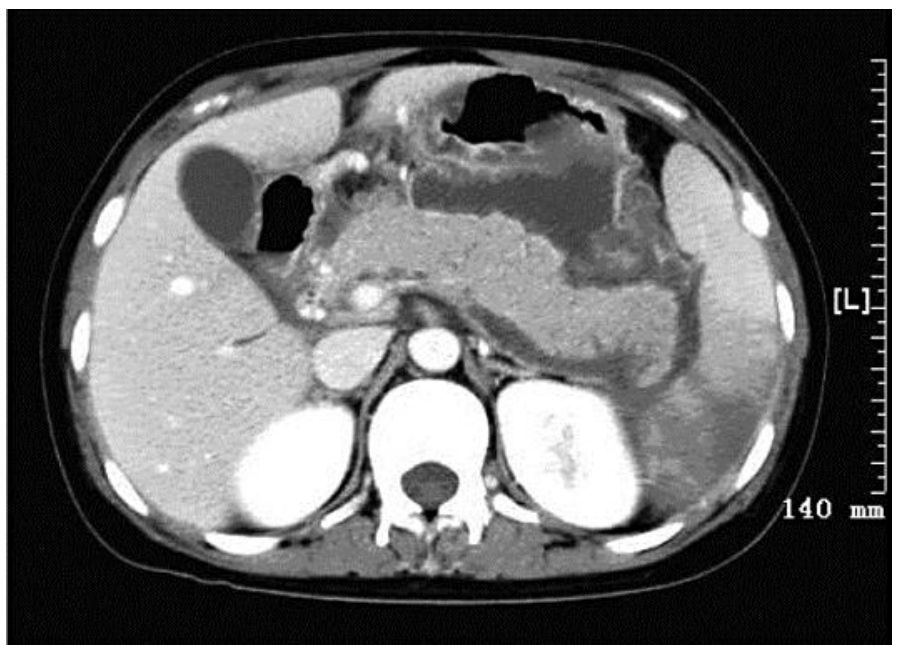

Fig. 1. Venous phase CT revealed thrombosis in the splenic vein and partial infarction of enlarged spleen.

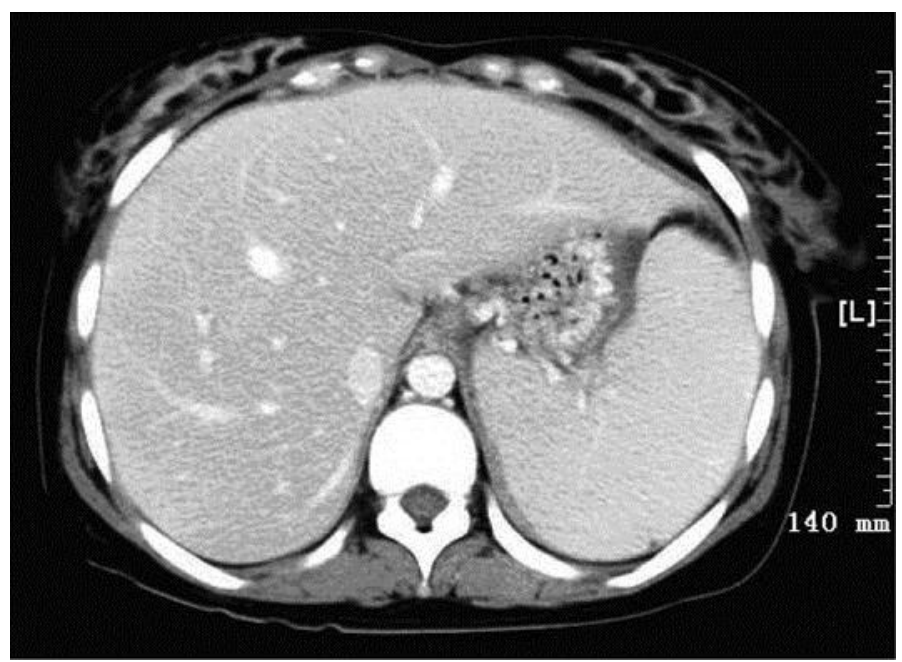

Fig. 2. Venous phase CT demonstrated gastric varices. 


\begin{tabular}{r|l|l|l}
$\begin{array}{r}\text { Case Reports in } \\
\text { Gastroenterology }\end{array}$ & $\begin{array}{l}\text { Case Rep Gastroenterol 2012;6:741-746 } \\
\text { DOI: 10.1159/000345962 }\end{array}$ & $\begin{array}{l}\text { Published online: } \\
\text { December 11, 2012 }\end{array}$ & $\begin{array}{l}\text { @ 2012 S. Karger AG, Basel } \\
\text { ISSN 1662-0631 } \\
\text { www.karger.com/crg }\end{array}$ \\
\hline
\end{tabular}

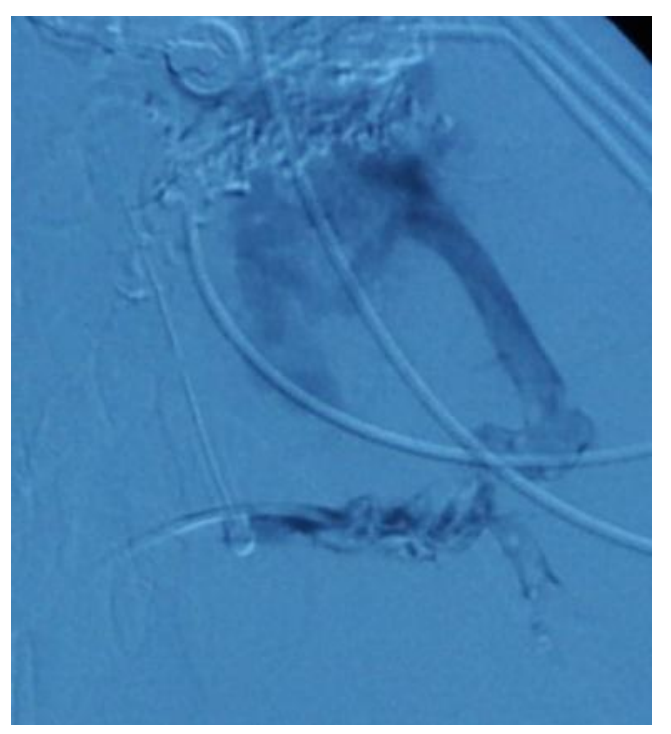

Fig. 3. Percutaneous transhepatic portography showed obstruction of the splenic vein and bleeding from one of the enlarged short gastric veins into the gastric cavity.

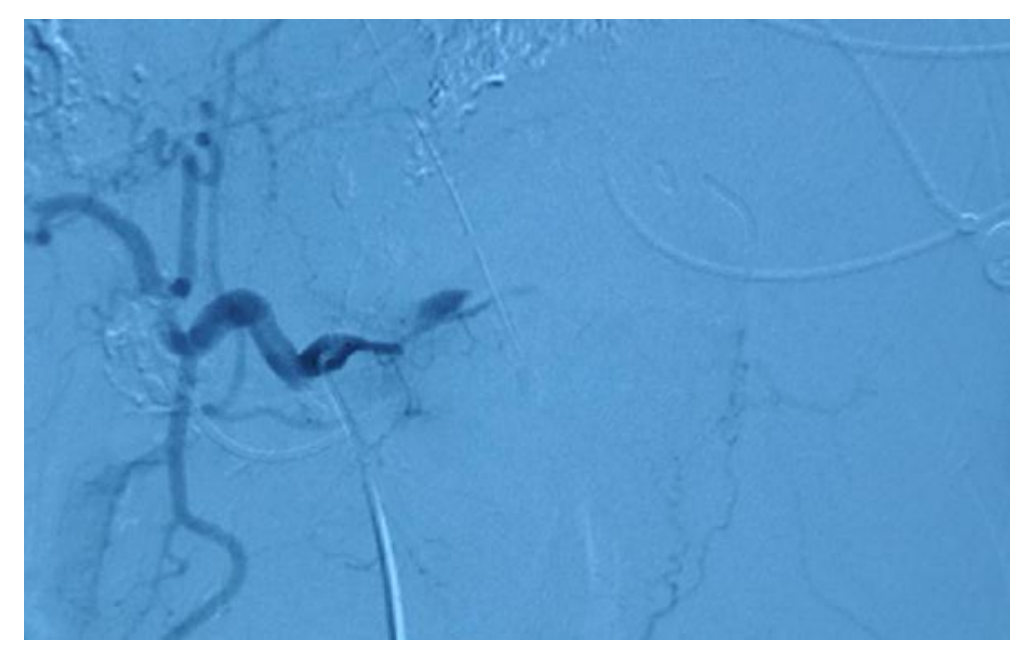

Fig. 4. Embolic agent of cellulose sponge plugs was injected into the splenic artery. 


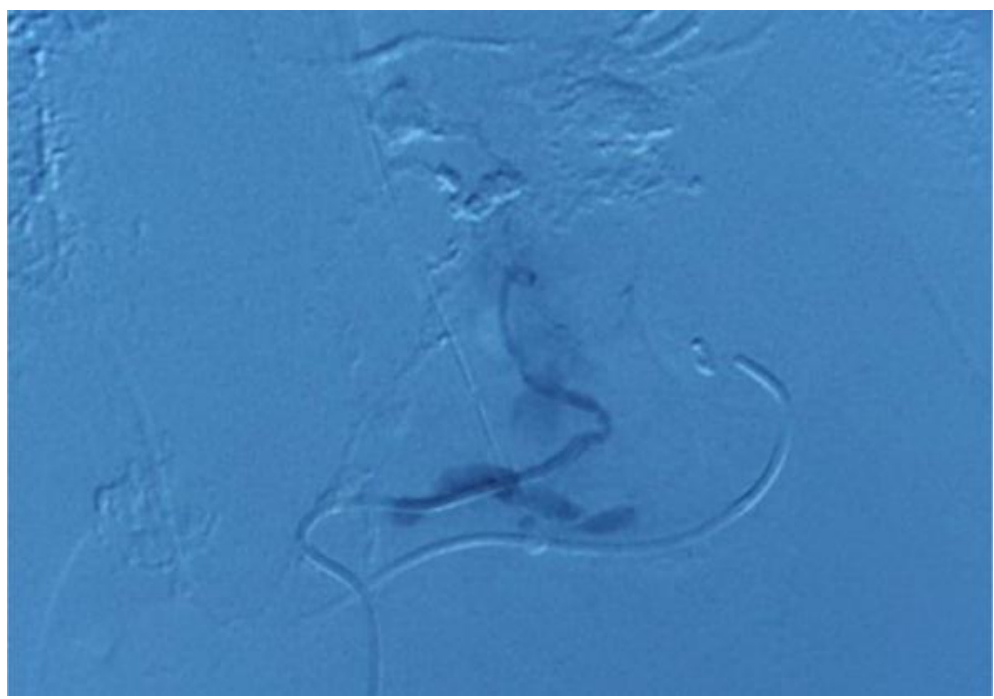

Fig. 5. Embolic agents of vascular coils were used in the enlarged short gastric vein

\section{References}

1 Kapoor S, Rao P, Pal S, Chattopadhyay TK: Hemosuccus pancreaticus: an uncommon cause of gastrointestinal hemorrhage. A case report. JOP 2004;5:373-376.

-2 Thompson RJ, Taylor MA, McKie LD, Diamond T: Sinistral portal hypertension. Ulster Med J 2006;75: 175-177.

-3 Paramythiotis D, Papavramidis TS, Giavroglou K, Potsi S, Girtovitis F, Michalopoulos A, Papadopoulos VN, Prousalidis J: Massive variceal bleeding secondary to splenic vein thrombosis successfully treated with splenic artery embolization: a case report. J Med Case Rep 2010;4:139.

4 Singhal D, Kakodkar R, Soin AS, Gupta S, Nundy S: Sinistral portal hypertension. A case report. JOP 2006;7:670-673.

5 Bose S, De Bakshi S, Banerjee A, Anklesaria D: Three cases of massive bleeding from pancreatic pseudocysts. HPB (Oxford) 2003;5:114-117.

-6 Stermer E, Elias N, Keren D, Rainis T, Goldstein O, Lavy A: Acute pancreatitis and upper gastrointestinal bleeding as presenting symptoms of a duodenal Brunner's gland hamartoma. Can J Gastroenterol 2006;20:541-542.

7 Sato T, Yamazaki K, Akaike J, Toyota J, Karino Y, Ohmura T: Clinical and endoscopic features of gastric varices secondary to splenic vein occlusion. Hepatol Res 2008;38:1076-1082.

-8 Lerch MM, Stier A, Wahnschaffe U, Mayerle J: Pancreatic pseudocysts. Dtsch Arztebl Int 2009;106: 614-621.

-9 Piotrowska SG, Sek G, Kukliński A, Wereszczyńska SU, Kedra B, Dabrowski A: Massive bleeding from the upper digestive tract in patients with pseudoaneurysm of splenic artery. Pol Merkur Lekarski 2006;20:698-701.

10 Poultsides GA, Kim CJ, Orlando R 3rd, Peros G, Hallisey MJ, Vignati PV: Angiographic embolization for gastroduodenal hemorrhage: safety, efficacy, and predictors of outcome. Arch Surg 2008;143:457-461.

11 Tripathi D, Ferguson JW, Therapondos G, Plevris JN, Hayes PC: Review article: recent advances in the management of bleeding gastric varices. Aliment Pharmacol Ther 2006;24:1-17.

12 Ou HY, Huang TL, Chen TY, Tsang LL, Concejero AM, Chen CL, Cheng YF: Emergency splenic arterial embolization for massive variceal bleeding in liver recipient with left-sided portal hypertension. Liver Transpl 2005;11:1136-1139.

13 Gong GQ, Wang XL, Wang JH, Yan ZP, Cheng JM, Qian S, Chen Y: Percutaneous transsplenic embolization of esophageal and gastrio-fundal varices in 18 patients. World J Gastroenterol 2001;7:880-883. 